Rev. Elev. Méd. vét. Pays trop., 1972, 25 (3) : 347-356

\title{
Deux maladies aviaires nouvelles au Tchad: la laryngotrachéite infectieuse et la maladie de Gumboro
}

\author{
par A. PROVOST (*), C. BORREDON (*) et P. BOCQUET (*)
}

\section{RESUME}

La laryngo-trachéite infectieuse, sous une forme particulièrement meurtrière, et la maladie de Gumboro sont apparues en 1971 dans les élevages améliorés de la région de Fort-Lamy.

En clinique courante, la pathologie infectieuse aviaire d'Afrique centrale est simple (8): variole et typhose à l'état enzootique, spirochétose dans la partie sahélienne, brèves mais meurtrières incursions de maladie de Newcastle.

Autour des grandes villes, se sont depuis quelques années créés des élevages améliorés; les poussins sont importés d'Europe. Avec eux sont venues les leucoses et la maladie respiratoire chronique puis se sont installés des microbismes banaux d'élevage. La prophylaxie médicale est simplifiée par l'utilisation d'un vaccin polyvalent, immunisant en une seule injection contre la maladie de Newcastle, la variole et la typhose $\left({ }^{* *}\right)$. Sur cette toile de fond rassurante, deux épisodes sont venus jeter une ombre.

A la fin de mai 1971, la brusque mortalité en une seule journée d'une dizaine de poules Warren du poulailler familial de l'un de nous a éveillé l'attention. Il s'agissait de poules

(*) I.E.M.V.T., Laboratoire de Recherches Vétérinaires de Farcha, B.P. no 433, Fort-Lamy, Tchad.

(**) Vaccin POLAVIA du Laboratoire de Farcha (8). adultes 2 fois vaccinées, entretenues en claustration sans introduction de sujets de l'extérieur. L'alimentation était à base d'un mélange fabriqué localement, l'abreuvement par eau de forage profond. Le reste des oiseaux encore vivants, une quarantaine au total, était prostré et présentait une détresse respiratoire intense; de temps à autre, l'un d'eux faisait entendre un cri strident, bref et monocorde, en même temps qu'il secouait violemment la tête et qu'une salive gluante coulait du bec. D'heure en heure, la mortalité augmentait; la totalité du poulailler était anéantie en 3 jours.

Le verdict nécropsique du technicien chargé de l'autopsie fut net: peste aviaire, appuyé qu'il était par la présence d'un piqueté hémorragique du proventricule et une intense atteinte laryngée, congestive et nécrosante (planche 1). Pour nous, un doute existait pourtant, apporté par l'anamnèse: sujets vaccinés, maladie à prédominance respiratoire sans manifestations nerveuses.

On réalise un prélèvement de mucus trachéal, un autre de rate qui sont tous deux ensemencés en cultures cellulaires de fibroblastes de poulet; en même temps sont effectués des examens 
bactériologiques de routine et des coupes histologiques de trachée.

L'existence d'une importante nécrose de l'épithélium trachéal avec la présence de quelques cellules à inclusions nucléaires et margination de la chromatine aiguillait vers le diagnostic de laryngo-trachéite infectieuse (planche 2). Le virus était isolé en cultures cellulaires, où il produit un effet cytopathique caractéristique : nécrose en nappe de couches cellulaires accompagnée de la formation de plasmodes multinuclées dont les noyaux présentent des inclusions du type A de COWDRY (planche 2).

$\mathrm{Au}$ total, le diagnostic était facile à poser. Néanmoins, on pouvait être surpris par l'ampleur de la mortalité, ce qui n'est pas classique dans la laryngo-trachéite où elle se limite, selon les classiques, à 40 p. 100.

Soit du poulailler atteint, soit procédant de la même source d'infection, la maladie s'étendait à plusieurs élevages du village de Farcha qui, dans leur presque totalité, furent décimés. Il était pourtant caractéristique de voir, dans un même village, certains parquets touchés à côté d'autres restant indemnes.

Puis, comme elle était apparue, la maladie brusquement disparut. Ce n'est que très récemment, en janvier 1972, qu'elle vient de faire sa réapparition dans un élevage de 2.000 poules de ponte qui sont toutes mortes en l'espace de quelques jours $\left(^{*}\right)$.

De là, elle s'est de nouveau manifestée dans deux parquets du village de Farcha, puis dans la poussinière du Service de l'Elevage où toutes les volailles ont été décimées. Nous reviendrons plus loin sur ce dernier cas, riche d'enseignements cliniques.

De ces épisodes, il est plusieurs points à retenir :

- toute mortalité aviaire n'est pas forcément « la peste » comme ont tendance à le proclamer les personnes non informées ou les cliniciens n'effectuant qu'une enquête superficielle. Pourtant, il est vrai que la présence de points hémorragiques sur les follicules du proventricule pouvaient en imposer pour le diagnostic nécropsique de maladie de Newcastle. Cette

(*) Hormis 200 vaccinées par voie cloacale avec un vaccin dont on parlera plus loin. lésion n'a rien de courant dans la laryngotrachéite et, dans le cas présent, on peut se demander si une autre virose sous-jacente n'est pas elle aussi présente. Par contre, l'intensité de l'atteinte trachéale est sans aucune commune mesure avec celle que l'on pourrait rencontrer dans la maladie de Newcastle.

- l'origine de la maladie est mystérieuse. Elle ne correspond à aucune importation de poussins ni à aucune introduction de poules locales dans les élevages. Sa marche l'est tout autant: il est classique d'admettre que seul le poulet est naturellement réceptif et que le virus n'est pas spécialement résistant dans le milieu extérieur, on explique difficilement l'apparition de foyers différés dans l'espace et le temps, à moins qu'ils n'aient tous la même origine non identifiée.

Il est difficile d'admettre que l'importation du virus puisse être attribuée à des poussins d'un jour achetés en Europe. Ce n'est pas chez de tels sujets que la maladie est apparue, mais chez des adultes puis des poulets.

Corollaire de cette question se pose celle d'un hypothétique réservoir de virus dans le milieu tchadien. Pourquoi cette résurgence dans un autre élevage sans aucun contact avec les premiers, situés à une vingtaine de kilomètres de distance ? Pourquoi, ensuite, cette extension à la poussinière qui est séparée du reste des parquets et en complète claustration?

- la morbidité, la mortalité et la rapidité de l'évolution sont anormalement élevées. Alors que les atteintes primitives de laryngo-trachéite infectieuse n'entraînent classiquement qu'une mortalité de 40 p. 100 au maximum (1), voire 10 à 15 p. 100 seulement s'étalant sur une quinzaine de jours, c'est à 90 p. 100 en 2 ou 3 jours qu'on peut estimer celle qui a été relevée à Fort-Lamy. Là encore des questions se posent: réceptivité particulière de certaines souches de volailles dans le contexte écologique tchadien? Il a en effet paru que la souche Warren SSLL était particulièrement touchée mais des poulettes Hy-line et Silver-cross l'ont été tout autant, alors que d'autres souches élevées en étroite cohabitation sont restées indemnes.

Virus à pouvoir pathogène exalté ? La reproduction de la maladie par inoculation intratrachéale du virus de premier passage en cultures 
cellulaires a permis d'observer la génèse puis l'évolution des symptômes mais n'a conduit qu'à une mortalité de 15 p. 100 , c'est-à-dire celle qu'il est normal de constater.

Il est vraisemblable, au regard des isolements de bactéries diverses (colibacille, pseudomonas, mycoplasmes et même une salmonelle du groupe sérologique OMA) réalisées concomitamment à celui du virus, qu'un microbisme d'élevage a fragilisé la résistance des oiseaux. C'est donc plutôt à l'action pathogène d'un ensemble de causes que l'on doit d'avoir eu une mortalité aussi importante. Dans cet ordre d'idée, on notera que les jeunes poulets de la poussinière étaient en même temps touchés par la maladie de Gumboro. N'est-ce point cette dernière, diagnostiquée à quelques jours de la première atteinte de laryngo-trachéite, qui peut être tenue pour responsable des lésions hémorragiques du proventricule?

$\mathrm{Au}$ total, l'existence nouvelle de la laryngotrachéite infectieuse aviaire sous une forme particulièrement meurtrière, compte tenu des observations épidémio-cliniques rapportées, va poser de sérieux problèmes dans l'avenir: vat-on devoir systématiquement vacciner contre elle, ou rester dans l'expectative, quitte à intervenir rapidement si elle se manifeste et que le diagnostic exact soit posé?

Dans l'immédiat, on peut proposer l'utilisation d'un "vaccin de guerre " très simplement préparé par raclage du mucus trachéal sur des poules abattues lors du début d'une épizootie; le mucus est mis en suspension au 1/10 et homogénéisé dans une solution physiologique phosphatée à $\mathrm{pH}: 7,2$, contenant un mélange polyantibiotique destiné à détruire les bactéries adventices. La vaccination se réalise très simplement par brossage de la muqueuse cloacale avec une petite brosse ou un écouvillon trempé dans le vaccin conservé en glace fondante. Cette pratique, instaurée lors de la seconde incursion de l'infection, a permis de sauver un parquet de 200 poulettes non encore touché alors que les 6 parquets attenants ont été décimés.

Facile à réaliser, ce vaccin appelle pourtant des réserves : il faut être certain du diagnostic et ne pas confondre, par exemple, avec une authentique maladie de Newcastle. La concomitance d'une autre virose, telle la maladie de
Gumboro, doit aussi être écartée. Pour ces raisons, il est vraisemblable que l'avenir de la vaccination sera l'utilisation d'un virus-vaccin atténué.

C'est à quelques jours de la première reconnaissance de la laryngo-trachéite infectieuse que l'on a été amené à soupçonner très fortement l'existence de la maladie de Newcastle sur des poulets d'élevages du village de Farcha âgés de 6 semaines, présentés à l'autopsie: intense piqueté hémorragique de la muqueuse interne du ventricule succenturié et de la paroi intestinale, présence (inconstante) du même piqueté sur le cloaque, absence de lésions trachéales. Pourtant, la réaction de diagnostic rapide de Mc CLURKIN, SHINA et HANSON (6) restait négative et les liquides allantoïques des œufs embryonnés inoculés depuis 48 heures avec des extraits d'organes ne présentaient aucun pouvoir hémagglutinant. Un doute s'installait alors, corroboré par la connaissance d'une vaccination anti-Newcastle vieille de 3 semaines.

Un examen plus approfondi de nouvelles carcasses soumises à l'autopsie permettait de décele; , en plus d'intenses hémorragies du proventricule à sa jonction avec le gésier, une hypertrophie de la bourse de Fabricius dont la partie séreuse présentait des plaques hémorragiques chez quelques sujets, une atteinte rénale, caractérisée par une hypertrophie de l'organe dont les tubes urinifères étaient dilatés et saillants et, enfin, des hémorragies des masses musculaires du bréchet ou des cuisses, allant d'un piqueté à de larges flaques interfasciales (planche 3).

Ce tableau nécropsique typique aiguillait vers le diagnostic de maladie de Gumboro $(4,5,7)$. Effectivement, la section des bourses de Fabricius montrait un épaississement, parfois accompagné de congestion et d'hémorragies, des lamelles internes de l'organe. Des coupes histologiques permettaient de noter une intense infiltration œdémateuse médio-folliculaire avec nécroses et pycnoses cellulaires parfois organisées en foyers granulomateux (planche 3). Ces images sont caractéristiques de la maladie de Gumboro (7).

Un extrait d'organes traité par un mélange polyantibiotique et inoculé à l'œuf embryonné a déclenché une mortalité embryonnaire dans 
les 5 à 8 jours suivant l'inoculation. Les embryons morts étaient plus petits que les témoins non inoculés et présentaient des hémorragies cutanées.

Dans les deux élevages touchés, la mortalité cessait en une semaine, atteignant environ un quart de l'effectif au total.

Après ce premier épisode, le diagnostic nécropsique de la maladie de Gumboro a pu être porté à plusieurs reprises dans des élevages lamyfortains, $\mathrm{y}$ compris la poussinière où elle s'est manifestée en même temps que la laryngotrachéite.

Sans qu'on puisse l'affirmer, on est en droit de penser que cette maladie a été importée au Tchad avec des poussins. Son existence pose des problèmes pour l'avenir de l'aviculture car le virus est résistant dans le milieu extérieur et sa transmission est à la fois verticale et horizontale, voire même indirecte par les éleveurs eux-mêmes, les ustensiles d'élevage et les litières.

Virose touchant l'appareil lymphoïde immunoformateur, ne peut-on craindre un effet dépresseur pour les vaccinations ultérieures malgré les constatations rassurantes de RINALDI, CERVIO et MANDELLI (9) ?

Sans problèmes au début de son installation, l'aviculture améliorée tchadienne a vu se créer sa pathologie propre qui n'a rien de commun, hormis la variole et la spirochétose, avec la pathologie locale. Sans épiloguer sur le sujet, on notera que ses composantes principales sont d'apparition récente et que, maladies contagieuses, elles risquent de s'échapper hors du milieu qu'elles infectent actuellement.

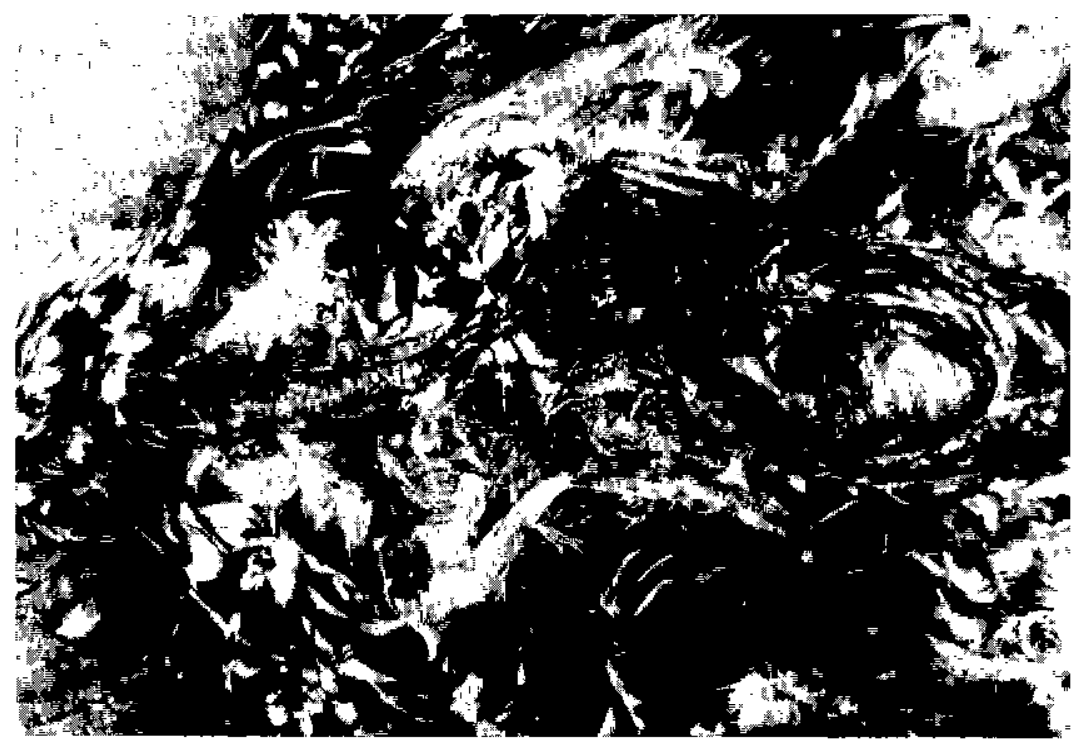

Fig. A. - Cadavre de poulet atteint de laryngo-trachéite infectieuse.

Noter l'intense atteinte laryngée et la présence de pétéchies dans le proventricule. 


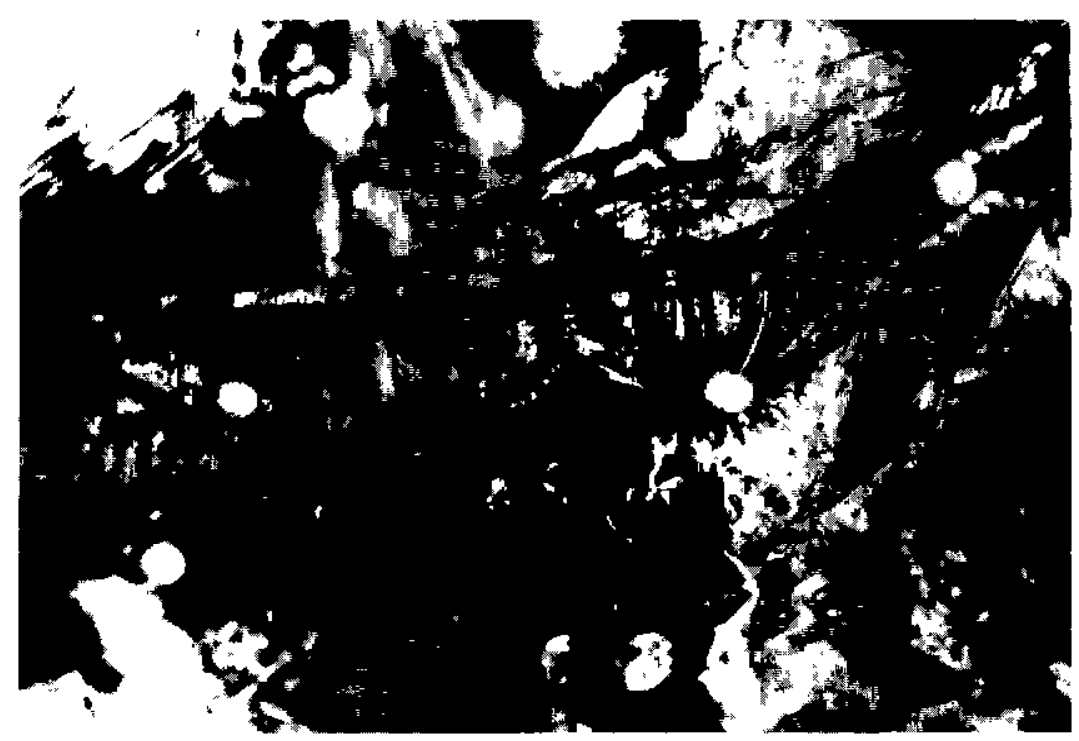

Fig. B. - Même cadavre. Vue agrandie de la trachée. Noter la congestion et la présence de bouchons de muco-pus.

Fig. C. - Même cadavre. Vue agrandie du proventricule.
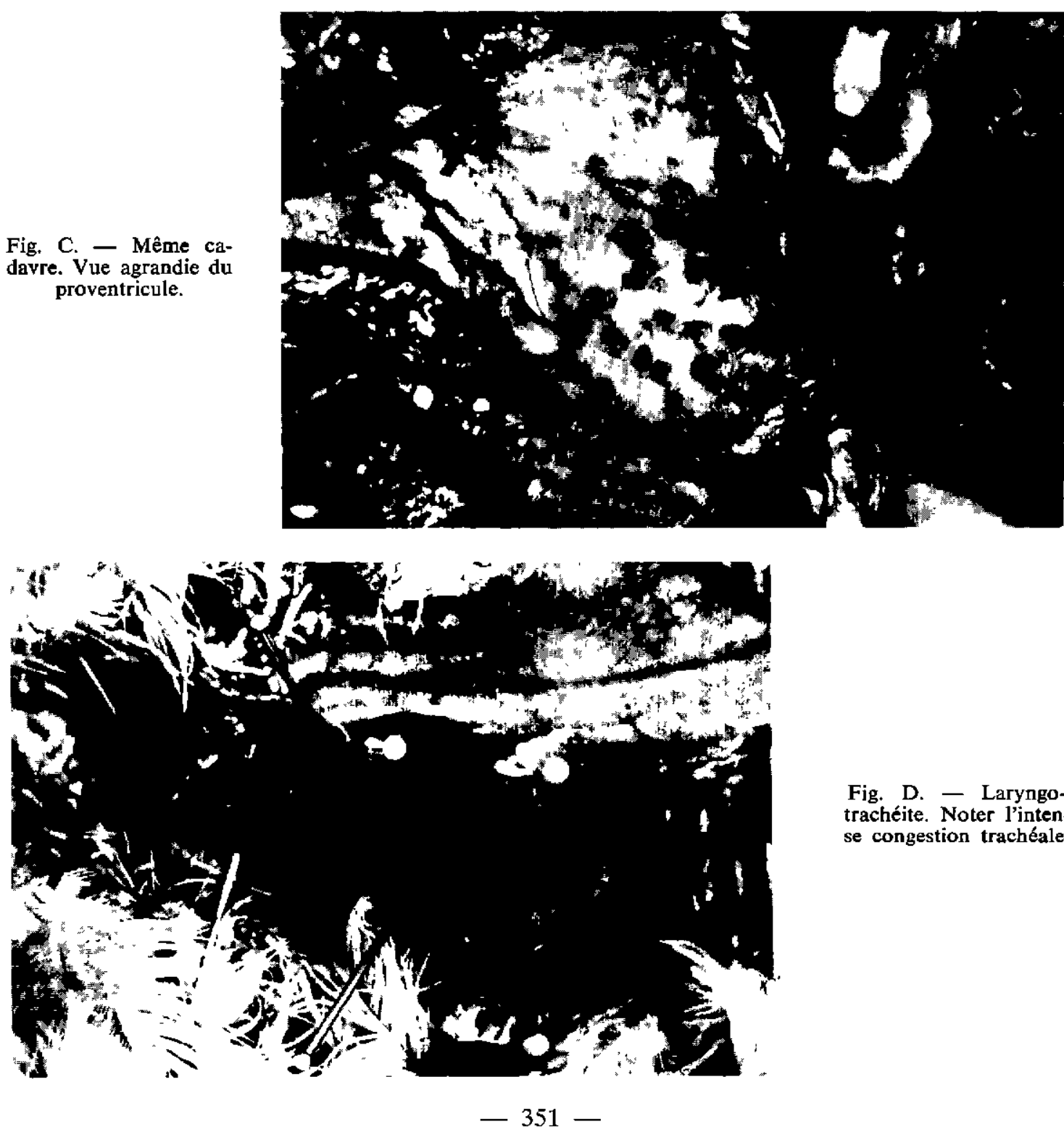

Fig. D. - Laryngotrachéite. Noter l'intense congestion trachéale. 


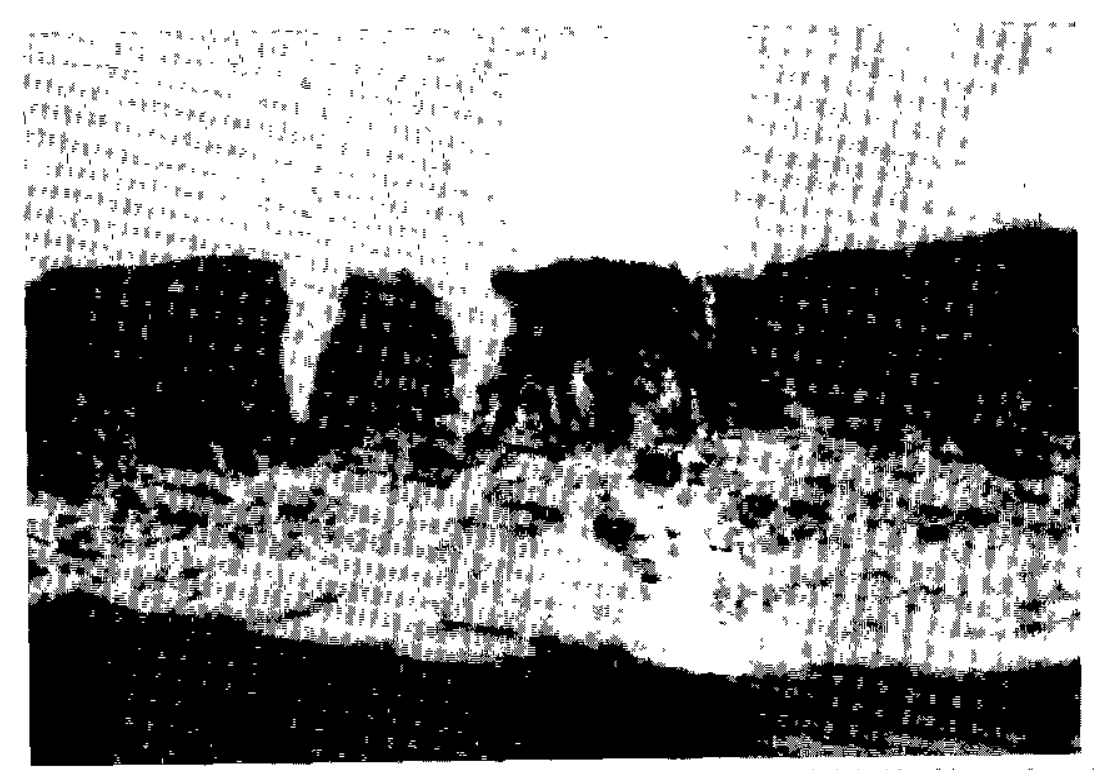

Planche 2.

Fig. A. - Laryngo-trachéite infectieuse. Trachée de poule. Noter l'infiltration cedémateuse de la sous-muqueuse, l'hyperplasie et l'infiltration leucocytaire de l'épithélium. $\mathrm{G}=125$.

Fig. B. - Même figure que la précédente, grossie. Noter la perte de la ciliature, la nécrose cellulaire et l'infiltration. $\mathrm{G}=300$.
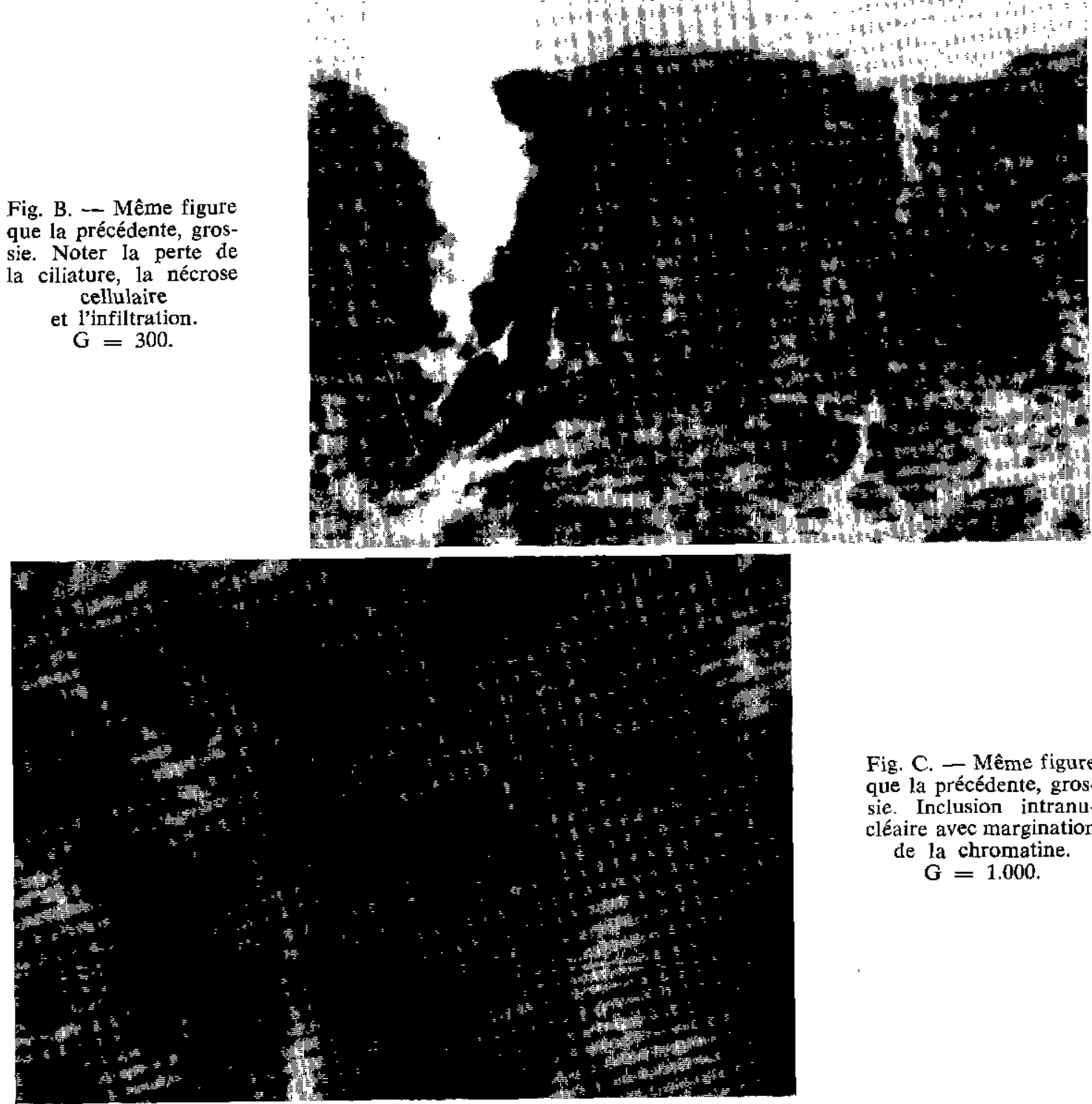

Fig. C. - Même figure que la précédente, grossie. Inclusion intranucléaire avec margination de la chromatine. $\mathrm{G}=1.000$. 

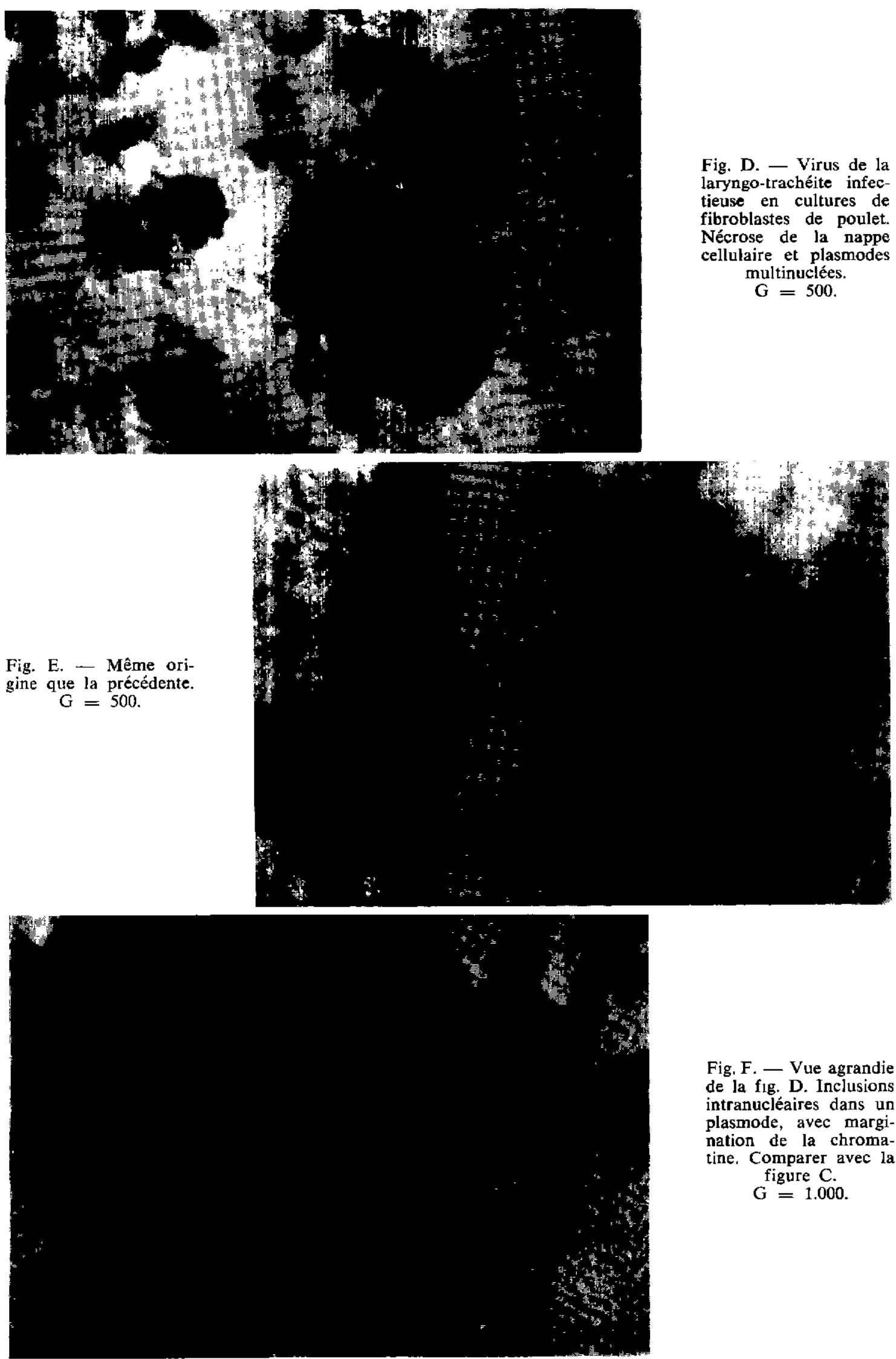

Fig, F. - Vue agrandie de la fig. D. Inclusions intranucléaires dans un plasmode, avec margination de la chromatine. Comparer avec la figure $\mathrm{C}$. $\mathrm{G}=1.000$. 


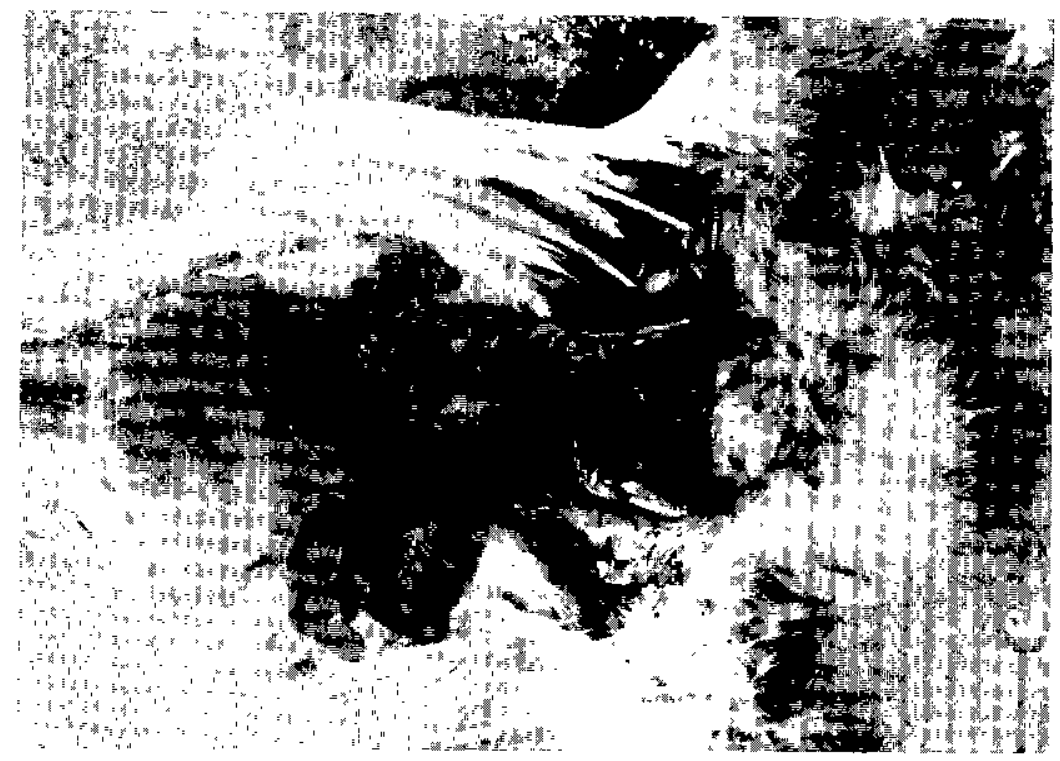

Planche 3.

Fig. A. - Maladie de Gumboro. Carcasse de poulet. Noter l'hypertrophie de la bourse de Fabricius et des reins.

Fig. B. - Maladie de Gumboro. Proventricule et gésier, Noter les nappes hémorragiques à la jonction des deux organes.
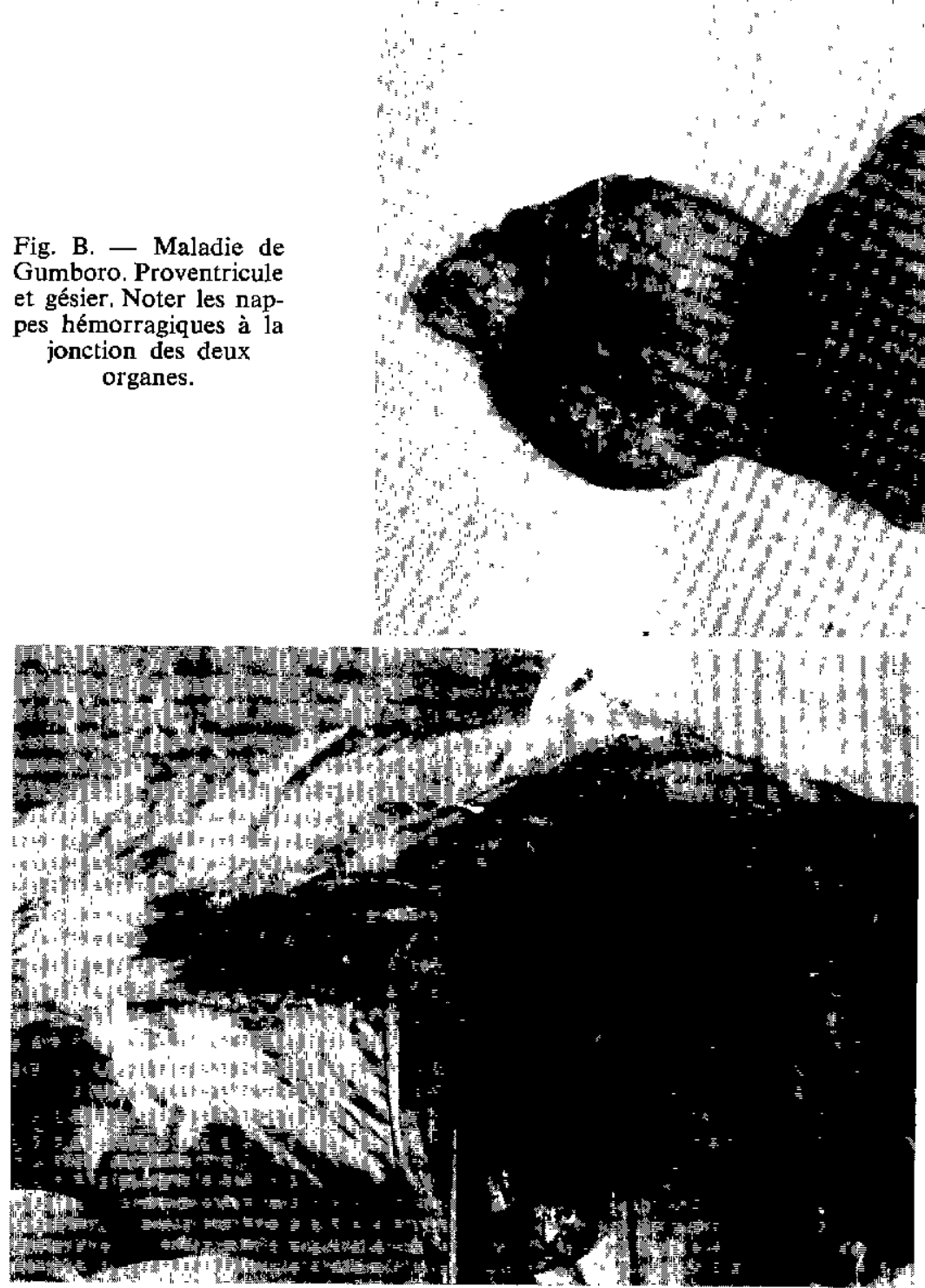

Fig. C. - Maladie de Gumboro.

Muscles pectoraux.

Noter les pétéchies. 


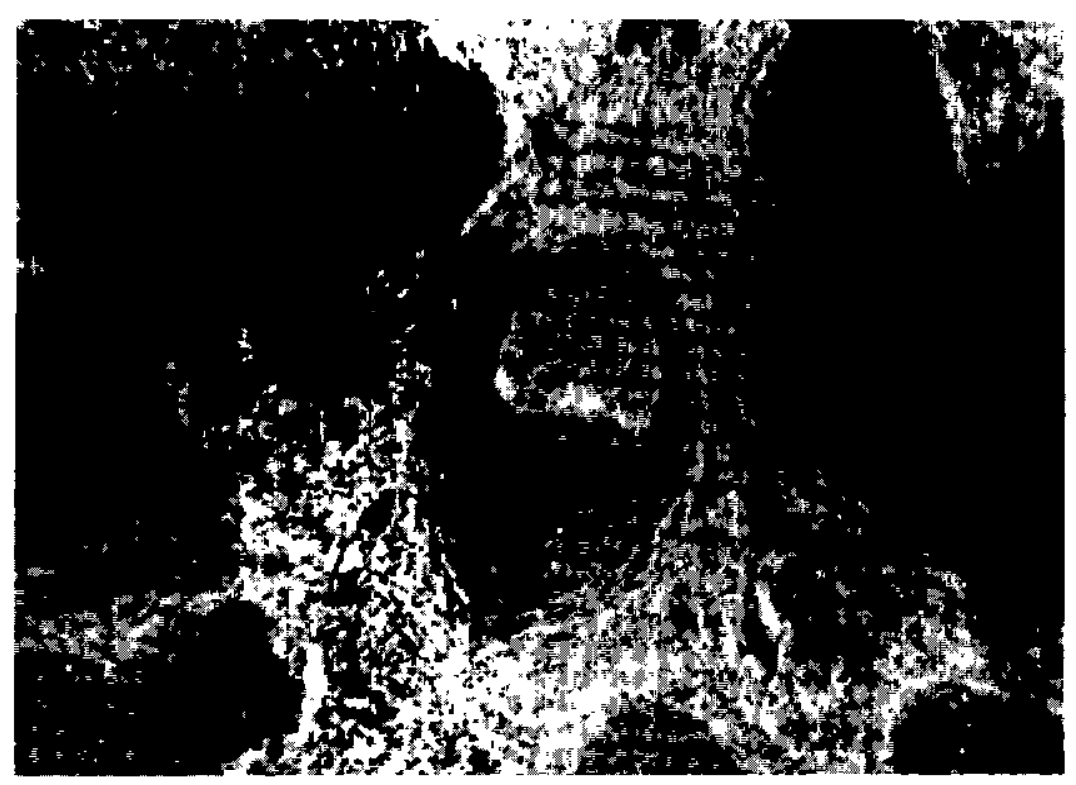

Fig. D. - Maladie de Gumboro. Coupe de la bourse de Fabricius.

Noter la nécrose cellulaire du centre des formations lymphoïdes. $G=300$.

\section{SUMMARY}

Two new avian diseases in Chad: infectious laryngo-tracheitis and Gumboro disease

Infectious laryngo-tracheitis with high mortality and Gumboro disease have been recorded in 1971 in modern-type flocks of the Fort-Lamy vicinity.

\section{RESUMEN}

Dos enfermedades aviarias nuevas en Chad :

la laringotraqueitis infecciosa $y$ la enfermedad de Gumboro

Aparecieron en 1971 la laringotraqueitis infecciosa, con una mortalidad elevada, y la enfermedad de Gumboro en crias mejoradas de aves de corral de la región de Fort-Lamy.

\section{BIBLIOGRAPHIE}

1. BIESTER (H.E.) et SCHWARTE (L.H.). Diseases of Poultry, 5e éd. Ames, Iowa (U.S.A.). The lowa State University Press, 1965.

2. GARSIDE (J.S.). The histopathological diagnosis of avian respiratory infections. Vet. Rec., 1965, 77 : 354-366.

3. HANSON (B.S.). Post-mortem lesions diagnostic of certain poultry diseases. Vet. Rec., 1967, 80 : 109-119

4. LENSING (H. H.). Gumboro disease. Neth. $J$. vet. Sci., 1969, 2 ; 117-124.

5. LUTHGEN (W.). Gumboro disease. Inf. Med. vet., 1969, (1): 3 .

6. Mc CLURKIN (A. W.), SINHA (S. K.) et HANSON (R. P.). Rapid diagnosis of Newcastle disease using lung extract. Am. J. ves. Res., 1954, 15 : 314-315.

7. MAIRE (C.), RENAULT (L.), ALAMAGNY (A.) et DREUILLE (M. de). Existence en France de la maladie de Gumboro. Rec. Méd. vét., 1969, 145: 75-84.

8. PROVOST (A.) et BORREDON (C.). Utilisation en Afrique centrale d'un vaccin aviaire polyvalent. Rev. Elev. Méd. vét. Pays trop., 1968, 21 : 165-180.

9. RINALDI (A.), CERVIO (G.) et MANDELLI (G.). Richerche sullo sviluppo della immunità vaccinale anti-pseudopeste in pulcini con « malattia di Gumboro » sperimentale. Clinica Vet., Milano, 1966, 89: 167-173. 